\title{
Application of simulation in determining suitable operating parameters for industrial scale fluidized bed dryer during drying of high impurity moist paddy
}

\begin{abstract}
A systematic approach has been developed for selecting the suitable drying parameters to be used for drying of high moisture and high impurity paddy with an industrial fluidized bed paddy dryer (10-20 t h-1 capacity) based on targeted specific air flow rate and residence time during two typical paddy drying seasons. A mathematical model was developed by modifying an existing model and was simulated and validated with observed industrial drying data as well as data reported in the literature. Comparison between the observed and simulated results showed that the mathematical model is capable of predicting outlet paddy moisture content and air temperature well. Suitable operating parameters were determined for reducing any initial paddy moisture content (mc) down to 24-25\% dry basis (db), the safe mc level after fluidized bed drying to maintain rice quality, to achieve maximum possible throughput capacity of the dryer with corresponding energy consumption. Based on these criteria, bed thickness at $10 \mathrm{~cm}$, specific air flow rate of $0.05 \mathrm{~kg} \mathrm{~kg}-1 \mathrm{~s}-1$ (for corresponding bed air velocity of $2.3 \mathrm{~m} \mathrm{~s}^{-1}$ ), air temperature of $150{ }^{\circ} \mathrm{C}$ and residence time of $1.0 \mathrm{~min}$ were found to be suitable drying conditions for reducing paddy mc from 30 to $24.30 \%(\mathrm{db})$ in one season while the maximum throughput capacity of 15.7 tonne per hour $(\mathrm{t} \mathrm{h}-1)$ might be achieved. The specific electrical and thermal energy were 0.48 and $6.15 \mathrm{MJ} \mathrm{kg}-1$ water evaporated, respectively. On the other hand, the dryer capacity was found to be limited to 7.4 $\mathrm{t} \mathrm{h}-1$ during drying paddy of higher initial mc $(35 \% \mathrm{db})$. This approach might provide easy and comprehensive guidelines for selecting suitable sets of operating parameters for any industrial fluidized bed dryer at its possible maximum throughput capacity for drying of freshly harvested high moist paddy with a high level of impurities.
\end{abstract}

Keyword: Industrial fluidized bed dryer; Simulation; Operating parameters; Dryer performance; Moisture removal; Specific energy consumption 